\title{
A Percepção de Marcas de Luxo em uma Era de "Populismo" de Réplicas: um Estudo a Partir da Ancoragem de Preços
}

\author{
The Perception of Luxury Brands \\ in an Era of Replicas of "Populism": \\ a Study from the Anchoring of Prices
}

\author{
JEFFERSON RODRIGUES PEREIRA* \\ CAISSA VELOSO E SOUSA** \\ ELIANE BRAGANÇA DE MATOS***
}

\section{RESUMO}

O presente trabalho teve por objetivo investigar o conhecimento das marcas de luxo e suas réplicas a partir da heurística cognitiva de ancoragem com base em preços. Foram escolhidas 14 marcas de luxo, em que os respondentes da pesquisa atribuíram valor ao produto original e a sua réplica, em duas etapas diferentes. Um total de 134 pessoas, escolhidas pelos critérios de acessibilidade e de conveniência, respondeu a um questionário on line. A primeira etapa da análise dos resultados mostrou, por meio do levantamento de dados extremos, que um significativo percentual de respondentes não conhecia as marcas. A segunda parte da análise mostrou que a ancoragem baseada nos preços das marcas originais funcionou de forma mais realista do que a situação contrária. Com base nestas análises foram feitas sugestões de modificação das estratégias de comunicação e direcionamento das

* Faculdade Novos Horizontes. Mestre em Administração pela Faculdade Novos Horizontes. Foi bolsista de Mestrado da Fundação de Amparo à Pesquisa do Estado de Minas Gerais (FAPEMIG). jeffersonrodrigues@live.com .

** Faculdade Novos Horizontes. Doutora em Administração de Empresas pela Universidade Federal de Minas Gerais, na linha de pesquisa de Administração Estratégica e Mercadologia. caissaveloso@yahoo.com.br .

*** Faculdade Novos Horizontes. Doutora e mestre em administração pelo CEPEAD / UFMG, com ênfase em marketing e comportamento do consumidor. É professora do Centro Federal de Educação Tecnológica - CEFET MG. elianebraganca@gmail.com . 
marcas de luxo de maneira a fortalecê-las e a facilitar o combate a pirataria e as falsificações.

Palavras-chave: Marcas de Luxo, Réplicas, Heurística da Ancoragem, Estratégia.

\section{Abstract}

The objective of this study was to investigate had knowledge of luxury brands and their replicas from the cognitive anchoring heuristic based on prices. It were selected 14 luxury brands, where survey respondents attributed value to the original product and its replica, in two different stages. A sample of 134 people, chosen by the criteria of accessibility and convenience, responded to a questionnaire on line. The analysis of outliers showed a significant percentage of respondents who do not know the brands. The second part of the analysis showed that anchor marks based on the original prices are better to identify replicas price than the opposite situation. Based on these analyzes were made suggestions to modify communication and targeting strategies of luxury brands in order to strengthen them and to facilitate the fight against piracy and counterfeiting.

Keywords: Luxury brands. Replicas. Anchoring Heuristic. Strategy.

\section{InTRODUÇão}

No cotidiano, quando as pessoas desconhecem as probabilidades associadas aos possíveis resultados de uma tarefa decisória, os julgamentos são realizados com a presença da incerteza, o que conduz a formação de simplificações ou atalhos mentais, chamados de heurísticas.

A área de investigação denominada de "Heurísticas" provém de pesquisas em Psicologia datadas das décadas de 1950 e 1960, que demonstraram que os julgamentos humanos são menos coerentes que os modelos matemáticos (TONETTO et al., 2006).

Em julgamentos sob incerteza, em situações em que os sujeitos devem realizar estimativas ou decidir sobre alguma quantia, há uma tendência de um ajustamento na resposta, fornecido com base em algum valor inicial disponível, que servirá como âncora. Esse atalho cognitivo corresponde à heurística de "ancoragem e ajustamento" 
(TVERSKY; KAHNEMAN, 1974), na qual a âncora proposta pode influenciar a resposta final.

Tversky e Kahneman (1974) popularizaram na literatura os termos ancoragem e ajustamento sobre julgamento e tomada de decisão, embora noções de ancoragem tenham sido introduzidas em descrições anteriores sobre inversões de preferências, quando há uma solicitação explícita para que as pessoas comparem o valor da âncora com o valor alvo (LICHTENSTEIN; SLOVIC, 1971).

Pesquisas mais recentes sugerem a origem da ancoragem como um estágio de recuperação de informação. Strack e Mussweiler (1997), Chapman e Johnson (1999) e Mussweiler e Strack (2001), por exemplo, demonstraram que a âncora age como uma sugestão, tornando mais disponível a informação, que é mais consistente com a âncora. Assim, estes estudos afirmam que a presença da âncora pode determinar qual informação será recuperada pelo indivíduo.

Segundo Chapman e Johnson (1999), os mecanismos da ancoragem e os seus efeitos são considerados robustos, apesar de ainda não estarem plenamente estabelecidos. A partir desse contexto, tomando-se como base a heurística de ancoragem e ajustamento, no presente estudo foram escolhidas 14 marcas, com representatividade no mercado de luxo (ABRAEL, 2013), para análise quanto a sua comparação com produtos considerados como réplicas.

A pergunta norteadora do estudo foi: "Qual o efeito da heurística de ancoragem na precificação de produtos originais em comparação as respectivas réplicas, dada a presença da marca?". Como objetivo geral pretendeu-se analisar o efeito da heurística de ancoragem entre a precificação de produtos originais e as respectivas réplicas, dada a presença de marca. De forma específica pretendeu-se: a) analisar a presença de ancoragem para as réplicas quando o preço do produto original é fixado; b) analisar a presença de ancoragem para os produtos originais quando o preço da réplica é fixado; c) identificar a influência sócio demográfica na ancoragem para os produtos analisados.

O trabalho está dividido em cinco seções. A primeira, que constitui essa introdução, apresenta a contextualização da temática, o problema e objetivos da pesquisa. Na segunda seção apresenta-se o argumento teórico que fornece embasamento para o estudo. A 
terceira seção apresenta os aspectos metodológicos, seguidos pela análise dos dados e considerações finais.

\section{REFERENCIAL TEÓRICo}

Esta seção apresenta a abordagem teórica que sustenta a discussão ora proposta. nesse sentido são discutidas temáticas relacionadas a marcas e heurísticas.

\subsection{Marcas: dimensões simbólicas e estratégicas}

As marcas passaram por evoluções e por transformações em sua lógica de funcionamento, na sua importância e em seu significado (SEMPRINI, 2010). Para Rao e Monroe (1989), a marca com maior influência no mercado é responsável pela qualidade percebida dos clientes, em comparação a atributos como preço e tamanho da empresa. Hoeffler e Keller (2003) ressaltam os diferenciais de uma marca influente no mercado, ao atestar que consumidores de marcas consolidadas reagem de maneira mais favorável às estratégias de Marketing.

O lugar que as marcas ocupam no mercado e nos espaços sociais foi alterado ao longo dos anos. Inicialmente, as marcas substituíam os produtos, os nomeando, os identificando e os diferenciando, permanecendo circunscrita ao universo do consumo nos médios e grandes centros comerciais (SEMPRINI, 2010). Atualmente, as marcas, em diferentes magnitudes, podem ser encontradas em locais diversos, mesmo os mais distantes dos grandes centros comerciais. Nesse sentido destaca-se que o consumo, na sociedade contemporânea, relaciona-se a um processo social, um mecanismo percebido como produtor de sentido e de identidades (BARBOSA; CAMPBELL, 2006).

Para Semprini (2010), a marca transforma-se em uma identidade relacional, pela sua dimensão intersubjetiva, como o resultado de um processo de trocas e negociações comerciais, e pela sua dimensão contratual, como resultado do reconhecimento pelos usuários de seu valor simbólico ou funcional. Uma marca com a qual o público estabelece um contrato é, por definição, uma marca que este mesmo público atribui valor e corresponde às suas necessidades.

$\mathrm{O}$ autor ainda afirma que o "caráter relacional da marca, em seus componentes intersubjetivos e contratuais, permite compreen- 
der quanto a noção de troca é central no funcionamento da marca contemporânea" (SEMPRINI, 2010, p. 107). Assim, para o autor, a marca é um lugar de encontro, um lugar em que as expectativas e as necessidades se encontram e estimulam o contrato.

De acordo com Crescitelli e Figueiredo (2009), as marcas podem agregar valores diferentes para os investidores, para os fabricantes, para os revendedores e para os consumidores, pois cada um desses grupos tem uma visão diferente sobre o significado do valor da marca. Para eles, torna-se importante compreender como o valor da marca pode ser criado e mantido na mente dos consumidores, traduzindo-se em hábitos de consumo e de compra.

\subsection{Marcas de luxo e réplicas}

Os produtos relacionados a uma determinada marca consagrada no mercado de produtos caros, originais e raros são denominados de produtos de luxo. Geralmente constituem mercadorias exclusivas e com garantia da origem, conferindo uma satisfação especial a seus consumidores, por sua raridade, pelo status adquirido por quem for seu proprietário ou pela consciência de que a posse de determinado produto remete a uma condição econômica elevada. $\mathrm{O}$ universo do luxo está associado a um nome, a uma individualidade (PEREIRA et al., 2007).

A Associação Brasileira de Empresas de Luxo (ABRAEL), em estudos sobre a riqueza mundial, divulgou que os principais setores do luxo no mercado brasileiro são moda e acessórios, cosméticos e perfumaria, joalheria e relojoaria, automóveis, hotelaria, bebidas e mobiliário. No Brasil, apenas $17 \%$ dos consumidores deste mercado possuem mais 55 anos e $84 \%$ possuem renda mensal superior a U\$ 6.000,00. As principais marcas apontadas desse mercado são: Louis Vuitton, Giorgio Armani, Chanel, Hermès, Marc Jacobs (ABRAEL, 2013).

No Brasil, o mercado de luxo movimentou aproximadamente $€ 3$ bilhões em 2013 (JORNAL DO BRASIL, 2013). O número de compradores regulares de produtos de luxo, no Brasil, gravita em torno de 300 - 500 mil consumidores (apenas 0,17 - 0,28\% da população). Para Galhanone (2013), o tamanho reduzido do potencial econômico e sua concentração geográfica, nas cidades como São Paulo, 
Brasília, Belo Horizonte e Rio de Janeiro, é considerado obstáculo para o desenvolvimento do mercado de luxo, além das dificuldades burocráticas, altos impostos de importação e as taxas locais, que tornam o preço final ao consumidor oneroso.

A definição de bens de luxo possui uma variedade temporal, modificando o rol destes produtos com o decorrer dos anos. A variedade também pode ser pessoal, em que o caráter subjetivo verifica se determinado produto confere ou não o status de luxo. A definição do conceito não está em um objeto em si, mas no julgamento sobre o seu valor pelos sujeitos (BATEY, 2010), o que pode garantir um símbolo de riqueza.

Para Lipovetsky e Roux (2005), a riqueza material está vinculada a um nome e a magia de uma marca. Para os autores, o consumo de produtos de luxo é impulsionado pela vaidade e pela estratégia de classificação social, que considera os bens por seu significado simbólico e não apenas por suas qualidades.

Um dos principais definidores de um bem de luxo é o seu preço. Tavares (2008) afirma que, com preços elevados, os produtos de luxo se distanciam da categoria de produtos de massa. Tal fato direciona o consumo destes bens a uma determinada classe econômica, com disponibilidade financeira para tal. Assim, a exclusividade se distancia da banalização. O respeito ao nome e a identidade da marca são mantidos, evitando-se a inflação de produtos de lançamento, efeitos de promoção e outros aspectos que podem, eventualmente, influenciar negativamente a identidade, o posicionamento e a imagem de determinada marca.

Nesse mesmo sentido, Douglas e Isherwood (2009) afirmam que os objetos de luxo podem ser usados como formas de exclusão social. A escala de consumo e o padrão de despesa são limitados pela renda, restringindo o acesso aos bens de luxo a determinada parcela da população. São produtos que não possuem o caráter da essencialidade das necessidades humanas, podendo seu consumo ser dispensado. O luxo não configura, portanto, uma necessidade e sim um desejo (CASTARÈDE, 2005).

Para Lipovetsky e Roux (2005), o consumo não se limita apenas ao que é necessário. Para os autores, tal fato ocorre em decorrência da supervalorização do consumo, do lazer e do bem-estar relaciona- 
dos à compra de produtos que podem ser considerados supérfluos. Neste aspecto, o bem luxuoso é, ao mesmo tempo, veículo para o prazer e instrumento de diferenciação social, de demonstração de riqueza e status.

As grandes marcas, vislumbrando o crescimento de suas vendas, passaram a produzir extensões de linhas de marcas famosas, produzidos em série, visando atender a uma parcela maior do mercado. Ao mesmo tempo, continuam a garantir o atendimento aos mais favorecidos financeiramente, que buscam exclusividade no luxo, por meio de suas marcas de alto padrão (CASTARÈDE, 2005).

Segundo Giesbrecht (2010), os diferentes significados agregados ao uso de uma determinada marca, reconhecida pelo mercado de luxo, impulsionam o mercado dos produtos paralelos constituído pelas réplicas ou falsificações. A definição destes conceitos torna-se necessária, pois, embora tratados como sinônimos por muitos autores, ambos apresentam significados diferentes e ocupam espaços distintos no mercado. O produto "réplica" indica uma similaridade com o original, porém deixa claro que os produtos não são idênticos. Por exemplo, nas réplicas copia-se a embalagem, mas não o produto (KLEIN, 2003; TRINDADE, 2008).

A falsificação é entendida como um crime contra a marca e também contra o consumidor, pois o produto apresenta características físicas e embalagens idênticas ao original, porém o item é falso (GIESBRECHT, 2010). A falsificação ocorre pela imitação dos elementos da marca, como a utilização das mesmas cores e design, de forma que a marca original empresta alguns elementos à marca pirateada.

No entanto, se esses aspectos são ilegais no mercado, podem não ser vistos da mesma forma pelos consumidores (STREHLAU; PETERS FILHO, 2006). A pesquisa destes autores aponta que para os entrevistados do grupo social que apresentou recente mobilidade social, a marca falsa pode servir como alavanca de potencialização de seu capital social, uma vez que tais marcas servem como muletas que demonstram uma posição social superior destes consumidores nos grupos sociais que extrapolam os limites de intimidade social. Ou seja, a marca falsificada de luxo pode ser uma demonstração de distinção deste consumidor em relação aos grupos sociais que não 
ascenderam na escala de consumo e como demonstração de aproximação e pertencimento aos segmentos de consumo almejados e superiores na escala social.

Ainda considerando o comportamento de consumo de marcas falsas ou réplicas, Gentry et al. (2001) aperfeiçoaram os conceitos de Grossman e Shapiro (1988) propondo três formas diferentes de relacionamento entre consumidor e produto falso: 1) os consumidores que esperam comprar um produto genuíno e o fazem; 2) os consumidores que esperam comprar um produto genuíno, mas acabam comprando uma falsificação; 3) os consumidores que esperam comprar um produto falsificado e o fazem, a isto denominam falsificação não enganadora, pois envolve pequeno risco físico, financeiro, e de performance para o consumidor. Os mesmos autores identificaram, também, que, alguns consumidores evitam a aquisição de produtos falsos por receio de serem "desmascarados" e identificados como "falsários" por conhecedores dos atributos e características dos produtos originais que lhes atribuem valor e diferenciais como de luxo.

\subsection{Heurísticas: ancoragem e ajustamento}

Considerando-se as limitações cerebrais humanas quanto à capacidade de processamento de informações, o cérebro cria atalhos mentais, que na literatura são chamados de heurísticas cognitivas, sendo elas utilizadas no processo de tomada de decisão (BEZERRA; LEONE, 2013). Segundo Tonetto et al. (2006), as heurísticas também podem ser vistas como regras de influência que os sujeitos utilizam para a formação de julgamento em processos de tomada de decisão sob condições de incertezas.

Por se tratarem de atalhos que reduzem a complexidade e o tempo necessário para a realização de algumas tarefas, as heurísticas podem levar a erros graves e sistemáticos (TVERSKY; KAHNEMAN, 1974). Nesse sentido, para Baker e Nofsinger (2002), na tentativa de diminuição da complexidade do processo decisório de informações que exigem uma maior análise do sujeito, o intelecto cria um filtro que bloqueia algumas dessas informações consideradas desnecessárias e utiliza algumas heurísticas no processo. Contudo, estes atalhos podem fazer com que o cérebro crie respostas antes 
do processamento integral de informações disponíveis, chamados de simplificação heurística, que podem levar o sujeito a vieses psicológicos e a erros de avaliação (BEZERRA; LEONE, 2013).

Uma das heurísticas mais comumente utilizadas, a ancoragem, é o processo pelo qual a mente do decisor dá preferência às primeiras informações que lhe são fornecidas (BEZERRA; LEONE, 2013). Segundo Tversky e Kahneman (1974), em processos de julgamentos sob elevado grau de incertezas, quando o indivíduo deve realizar estimativas ou até mesmo tomar decisões sobre alguma quantia, ele tende a criar uma estrutura psicológica a fim de ajustar sua resposta, tendo como base um valor inicial disponível, a chamada âncora. A este atalho cognitivo é dado o nome de heurística de "ancoragem e ajustamento", ou seja, trata-se de um processo pelo qual a âncora proposta inicialmente exerce influência sobre a decisão final do indivíduo.

Segundo Bezerra e Leone (2013) pode-se identificar a heurística da ancoragem quando um valor inicial é um referencial facilmente encontrado na predição de estimativas numéricas. Nesse sentido, Tversky e Kahneman (1974) afirmam que muitas decisões, principalmente aquelas tomadas em ambientes de incertezas e tensões, são tomadas com base em uma âncora que, por sua vez, é ajustada e levada à resposta final. Contudo, ainda segundo os autores, este ajustamento pode ser insuficiente e, consequentemente, enviesar o resultado final.

\section{Metodologia}

O presente estudo tem abordagem quantitativa e se caracteriza como descritivo, quanto aos fins. De acordo com Triviños (2012), a abordagem descritiva tem por finalidade descrever os fatos e fenômenos de uma determinada realidade. Para tal, o pesquisador deve se resguardar de informações primárias, além de delimitar técnicas, métodos, modelos e teorias que auxiliarão na coleta e tratamento dos dados.

Quanto aos fins a pesquisa se caracteriza como um estudo de campo, realizado por meio de uma survey online (COOPER; SCHINDLER, 2003). Para a realização da pesquisa foram escolhidas 14 marcas de luxo que, de acordo com ABRAEL (ABRAEL, 2013), possuem relevância significativa no mercado de luxo e são marcas referentes 
a diferentes segmentos, como vestuário, relógios, bolsas, sapatos, tênis, perfumes, joias e canetas. As marcas escolhidas foram Louis Vuitton, Tommy Hilfiger, H Stern, Diesel, Mont Blanc, Calvin Klein, Dolce \& Gabanna, Dior, Lacoste, Rolex, Prada, Chanel, Gucci e Nike.

A pesquisa foi dividida em duas etapas. Na primeira, os participantes visualizavam a imagem das marcas de luxo com o seu respectivo preço fixado. Na sequência era apresentada, para cada produto de luxo, uma réplica, para as quais os entrevistados deveriam atribuir um valor financeiro, que julgassem justo. Após a finalização do procedimento para as 14 marcas de luxo, iniciava-se a segunda etapa. Nessa os respondentes visualizavam inicialmente a marca réplica, ou seja, uma imagem análoga à do produto de luxo, porém com um nome fictício. A partir da imagem dessa réplica, e com um valor referencial de preço informado, para o qual foi atribuído um valor de mercado, os participantes deveriam fazer a precificação do valor da marca original, conforme julgassem justo.

Os respondentes foram contatados por acessibilidade, por meio da base de dados dos pesquisadores, e solicitados a preencher o questionário por meio de um link fornecido. Foi solicitado a esses contatos iniciais indicassem novos contatos para que respondessem ao questionário, configurando a técnica de bola de neve.

O Quadro 1 apresenta a relação de imagens, marcas e valores dos produtos utilizados na pesquisa.

Quadro1 - Relação das marcas trabalhadas

\begin{tabular}{|c|c|c|c|c|c|}
\hline \multicolumn{3}{|c|}{ Marca Original } & \multicolumn{3}{|c|}{ Marca Réplica } \\
\hline Imagem & Marca & Preço fixado & Imagem & Marca & $\begin{array}{l}\text { Preço } \\
\text { fixado }\end{array}$ \\
\hline$\underline{\mathrm{X}}$ & $\begin{array}{l}\text { Louis } \\
\text { Vuitton }\end{array}$ & $\mathrm{R} \$ 4.950,00$ & & $\begin{array}{l}\text { Lume } \\
\text { Vita }\end{array}$ & $\begin{array}{l}\mathrm{R} \$ \\
250,00\end{array}$ \\
\hline & $\begin{array}{l}\text { Tommy } \\
\text { Hilfiger }\end{array}$ & $\mathrm{R} \$ 460,00$ & & NewCase & $\mathrm{R} \$ 80,00$ \\
\hline
\end{tabular}




\begin{tabular}{|c|c|c|c|c|c|}
\hline \multicolumn{3}{|c|}{ Marca Original } & \multicolumn{3}{|c|}{ Marca Réplica } \\
\hline Imagem & Marca & Preço fixado & Imagem & Marca & $\begin{array}{l}\text { Preço } \\
\text { fixado }\end{array}$ \\
\hline & H Stern & $\mathrm{R} \$ 6.500,00$ & & $\begin{array}{l}\text { Ouro } \\
\text { Fino }\end{array}$ & $\begin{array}{l}\mathrm{R} \$ \\
2.500,00\end{array}$ \\
\hline & Diesel & $\mathrm{R} \$ 870,00$ & & Fuel & $\begin{array}{l}\mathrm{R} \$ \\
150,00\end{array}$ \\
\hline & $\begin{array}{l}\text { Mont } \\
\text { Blanc }\end{array}$ & $\mathrm{R} \$ 1.450,00$ & & Diamond & $\mathrm{R} \$ 40,00$ \\
\hline & $\begin{array}{l}\text { Calvin } \\
\text { Klein }\end{array}$ & $\mathrm{R} \$ 430,00$ & & Vivace & $\mathrm{R} \$ 80,00$ \\
\hline & $\begin{array}{l}\text { Dolce \& } \\
\text { Gabbana }\end{array}$ & $\mathrm{R} \$ 5.800,00$ & & $\begin{array}{l}\text { Légers } \\
\text { Chics }\end{array}$ & $\begin{array}{l}\mathrm{R} \$ \\
200,00\end{array}$ \\
\hline & Dior & $\mathrm{R} \$ 730,00$ & & Viber & $\begin{array}{l}\mathrm{R} \$ \\
120,00\end{array}$ \\
\hline & Lacoste & $\mathrm{R} \$ 250,00$ & & Lobster & $\mathrm{R} \$ 50,00$ \\
\hline & Rolex & $\mathrm{R} \$ 22.500,00$ & & Luxe & $\begin{array}{l}\mathrm{R} \$ \\
350,00\end{array}$ \\
\hline 选 & Prada & $\mathrm{R} \$ 1.200,00$ & 逞图 & Scarpe & $\begin{array}{l}\mathrm{R} \$ \\
180,00\end{array}$ \\
\hline
\end{tabular}




\begin{tabular}{|c|c|c|c|c|c|}
\hline \multicolumn{3}{|c|}{ Marca Original } & \multicolumn{3}{|c|}{ Marca Réplica } \\
\hline Imagem & Marca & Preço fixado & Imagem & Marca & $\begin{array}{l}\text { Preço } \\
\text { fixado }\end{array}$ \\
\hline & Chanel & $\mathrm{R} \$ 1.350,00$ & & Charme & $\begin{array}{l}\mathrm{R} \$ \\
250,00\end{array}$ \\
\hline & Gucci & $\mathrm{R} \$ 1.500,00$ & & Gumme & $\begin{array}{l}\mathrm{R} \$ \\
120,00\end{array}$ \\
\hline & Nike & $\mathrm{R} \$ 600,00$ & & Eros & $\mathrm{R} \$ 80,00$ \\
\hline
\end{tabular}

Fonte: Desenvolvido pelos autores.

Ressalta-se que os produtos designados como réplicas constituem uma imagem semelhante a dos produtos originais. Nesse caso, todas as réplicas são fictícias e foram estabelecidas pelos pesquisadores, constituindo a mesma imagem do produto original, com uma designação de marca diferente, sendo este o único atributo que as diferenciam dos produtos originais.

\section{APRESEnTAÇÃo E ANÁlise dos dAdOS}

Os dados levantados nesta pesquisa foram analisados a partir de 3 bases. A primeira foi a caracterização dos respondentes quanto aos critérios utilizados na pesquisa. Na segunda parte foi feita uma análise dos dados extremos, detectados em volume expressivo na pesquisa. E por último uma análise de diferenças e amplitude de diferenças entre valores fixados e atribuídos pelos respondentes.

\subsection{Caracterização dos Respondentes}

A amostra desta pesquisa foi constituída por 134 respondentes, dos quais $65,0 \%$ são do sexo feminino e 35,0\% do sexo masculino. Quanto à faixa etária, 4,9\% dos respondentes possuem idade entre 
16 e 20 anos de idade; $46,2 \%$ entre 21 e 30 anos; $32,2 \%$ entre 31 e 45 anos; $15,4 \%$ entre 46 e 60 anos e 1,3\% tem idade acima de 65 anos.

Em relação à distribuição por renda, 2,1\% dos respondentes afirmaram não possuir renda na data da pesquisa; $21,7 \%$ declararam possuir renda de até $\mathrm{R} \$ 1.356,00 ; 38,5 \%$ entre $\mathrm{R} \$ 1.357,00$ a $\mathrm{R} \$$ 3.390,00; 24,5\% entre $\mathrm{R} \$ 3.391,00$ e $\mathrm{R} \$ 6.780,00 ; 7,0 \%$ entre $\mathrm{R} \$ 6.781,00$ e $R \$ 10.170,00 ; 4,9 \%$ entre $R \$ 10.171,00$ e $R \$ 13.560$ e $1,4 \%$ possuem renda superior a $\mathrm{R} \$ 13.561,00$.

A maior parte da amostra $(59,4 \%)$ foi constituída por solteiros; $29,4 \%$ são casados ou possuem união estável; 0,7\% são viúvos; $9,1 \%$ são divorciados ou desquitados e 1,4\% marcaram o estado civil outros.

\subsection{Análise de dados extremos}

A análise exploratória dos dados identificou uma série de valores que podem ser considerados extremos, ou seja, observações cujas características revelavam-se destoantes, dadas as referências de valores fornecidas (HAIR JR et al., 2009). Por exemplo, quando se fixou um valor referencial para o preço de uma marca original e solicitou-se um preço para a marca réplica, esperava-se que os entrevistados respondessem com valores inferiores ao valor fixado. As respostas com valores para as réplicas iguais ou superiores aos valores fixados para as marcas originais foram considerados valores extremos. Da mesma maneira, quando foram fixados valores para as réplicas e solicitaram-se respostas para as marcas originais esperava-se que estes valores fossem superiores. Os valores respondidos em relação às marcas originais iguais ou inferiores ao valor fixado para as marcas réplicas foram, também, considerados como extremos.

Neste sentido resolveu-se iniciar esta análise pelo levantamento das distribuições de frequências dos valores atribuídos às marcas réplicas e marcas originais pelos respondentes. Foi considerada a distribuição de frequência por percentis, que possibilita a identificação dos valores que demarcam a porcentagem dos respondentes que atribuíram valores iguais ou inferiores ao identificado. Por exemplo, quando se fixa o percentil 10, o valor encontrado de 150 significa que $10 \%$ dos respondentes atribuíram o valor de até 150 para a questão colocada. Para a análise dos dados desta pesquisa buscou-se, inicialmente, a fixação de percentis variados, de maneira 
a possibilitar grande amplitude de análise. A TAB. 1, a seguir, apresenta os dados atribuídos às marcas réplicas quando é sugerido o valor do produto original, distribuídos por vários percentis.

Tabela 1 - Distribuição de frequência dos valores atribuídos às marcas réplicas

\begin{tabular}{|c|c|c|c|c|c|c|c|c|c|c|c|c|c|}
\hline \multirow{2}{*}{ Marca } & \multicolumn{12}{|c|}{ Percentis } & \multirow{2}{*}{$\begin{array}{l}\text { Valor } \\
\text { fixado }\end{array}$} \\
\hline & 10 & 20 & 25 & 35 & 40 & 45 & 50 & 75 & 80 & 85 & 90 & 95 & \\
\hline Calvin $\mathrm{K}$ & 27 & 40 & 50 & 50 & 60 & 72 & 80 & 152 & 200 & 287 & 430 & 430 & 430 \\
\hline Chanel & 90 & 120 & 134 & 150 & 162 & 189 & 200 & 350 & 394 & 500 & 1000 & 1350 & 1350 \\
\hline Diesel & 80 & 97 & 100 & 120 & 145 & 150 & 150 & 275 & 388 & 542 & 870 & 870 & 870 \\
\hline Dior & 50 & 69 & 84 & 100 & 100 & 120 & 135 & 276 & 300 & 496 & 706 & 730 & 730 \\
\hline Dolce Gabana & 83 & 120 & 150 & 200 & 200 & 200 & 250 & 500 & 800 & 1200 & 4699 & 5800 & 5800 \\
\hline Gutti & 60 & 83 & 90 & 100 & 120 & 150 & 150 & 250 & 300 & 500 & 1000 & 1500 & 1500 \\
\hline H Stern & 70 & 180 & 300 & 600 & 800 & 1000 & 1000 & 3000 & 4500 & 5220 & 6500 & 6500 & 6500 \\
\hline Lacoste & 30 & 40 & 50 & 50 & 60 & 60 & 70 & 100 & 135 & 170 & 250 & 250 & 250 \\
\hline Louis Vuitton & 52 & 97 & 100 & 200 & 200 & 200 & 250 & 500 & 1000 & 1500 & 4900 & 4950 & 4950 \\
\hline Mont Blanc & 25 & 47 & 50 & 80 & 100 & 100 & 115 & 400 & 600 & 944 & 1450 & 1450 & 1450 \\
\hline Nike & 70 & 90 & 100 & 120 & 150 & 150 & 150 & 300 & 300 & 378 & 570 & 600 & 600 \\
\hline Prada & 76 & 100 & 108 & 150 & 150 & 150 & 170 & 300 & 350 & 500 & 1125 & 1200 & 1200 \\
\hline Rolex & 150 & 200 & 200 & 350 & 450 & 500 & 650 & 3000 & 5000 & 10000 & 14100 & 22500 & 22500 \\
\hline Tommy H. & 50 & 68 & 80 & 100 & 100 & 100 & 120 & 224 & 300 & 373 & 460 & 460 & 460 \\
\hline
\end{tabular}

Fonte: Dados da pesquisa processados no SPSS

Os dados da TAB. 1 mostram que, fixados os valores para as marcas originais, 5\% (equivalente ao percentil 95) dos respondentes atribuíram valores iguais ou superiores a estes para as marcas réplicas. No caso das marcas H Stern, Dolce Gabana, Louis Vuitton, Mont Blanc, Prada Diesel, Tommy Hilfiger, Calvin Klein e Lacoste este percentual aumenta para $10 \%$.

Por outro lado, considerou-se, como exercício de análise, que as marcas réplicas deveriam, mesmo considerando-se a sua aceitação como produtos falsificados, terem seu valor atribuído em pelo menos igual a $10 \%$ do valor da marca original, uma vez que, mesmo destituídas do valor simbólico construído pela marca original, permaneceriam com um mínimo de valor de uso dos objetos que 
representam. Segundo esta proposição analítica, as marcas originais com valores monetários mais elevados tendem a ter o valor atribuído de suas réplicas em parâmetros inferiores a 10\% das marcas originais. Pelo menos $25 \%$ dos entrevistados atribuíram valores às réplicas inferiores a $10 \%$ do valor fixado para a marca original, quando estes superaram $\mathrm{R} \$ 1.200,00$. Estes dados apontam que quanto mais cara a marca maior é a tendência de desconhecimento de preços aceitáveis para suas réplicas.

A TAB. 2 apresenta a mesma análise por percentis, considerando-se, porém, a fixação de valores para as marcas originais e os valores das marcas réplicas atribuídos pelos respondentes da pesquisa.

Tabela 2 - Distribuição de frequência dos valores atribuídos às marcas originais

\begin{tabular}{|c|c|c|c|c|c|c|c|c|c|c|c|c|c|}
\hline \multirow{2}{*}{ Marca } & \multicolumn{12}{|c|}{ Percentis } & \multirow{2}{*}{$\begin{array}{l}\text { Valor } \\
\text { fixado }\end{array}$} \\
\hline & 10 & 20 & 25 & 35 & 40 & 45 & 50 & 75 & 80 & 85 & 90 & 95 & \\
\hline R Calvin K & 50 & 80 & 80 & 80 & 100 & 120 & 150 & 300 & 367 & 520 & 830 & 2800 & 80 \\
\hline R Chanel & 127 & 250 & 250 & 250 & 250 & 300 & 350 & 700 & 910 & 1200 & 1660 & 2500 & 250 \\
\hline R Diesel & 108 & 150 & 150 & 150 & 150 & 200 & 250 & 500 & 600 & 800 & 900 & 1500 & 150 \\
\hline R Dior & 100 & 120 & 120 & 120 & 150 & 160 & 200 & 350 & 467 & 525 & 784 & 1200 & 120 \\
\hline R Dolce Gabana & 150 & 200 & 200 & 200 & 250 & 300 & 350 & 680 & 810 & 1000 & 1500 & 2500 & 200 \\
\hline R Gutti & 94 & 120 & 120 & 120 & 150 & 196 & 200 & 400 & 500 & 740 & 900 & 1200 & 120 \\
\hline R H Stern & 350 & 1000 & 1500 & 2500 & 2500 & 2500 & 2500 & 5000 & 5000 & 6000 & 8020 & 10400 & 2500 \\
\hline R Lacoste & 50 & 50 & 50 & 80 & 90 & 100 & 100 & 250 & 250 & 308 & 500 & 2402 & 50 \\
\hline $\begin{array}{l}\text { R Louis } \\
\text { Vuitton }\end{array}$ & 132 & 250 & 250 & 250 & 380 & 500 & 500 & 2500 & 3000 & 3880 & 4980 & 5640 & 250 \\
\hline R Mont Blanc & 40 & 40 & 40 & 60 & 80 & 100 & 120 & 400 & 760 & 1000 & 1500 & 3220 & 40 \\
\hline R Nike & 80 & 80 & 100 & 150 & 180 & 200 & 200 & 490 & 532 & 600 & 730 & 800 & 80 \\
\hline R Prada & 138 & 180 & 180 & 180 & 186 & 240 & 250 & 400 & 800 & 1000 & 1290 & 1800 & 180 \\
\hline R Rolex & 300 & 350 & 350 & 500 & 700 & 850 & 1000 & 5000 & 7160 & 10000 & 14600 & 22400 & 350 \\
\hline R Tommy H. & 80 & 80 & 80 & 80 & 100 & 150 & 160 & 350 & 500 & 740 & 800 & 980 & 80 \\
\hline
\end{tabular}

Fonte: Dados da pesquisa processados no SPSS

Os dados da TAB. 2, que se referem os valores atribuídos às marcas originais pelos respondentes, a partir de valores fixados para as marcas réplicas, indica que $35 \%$ dos respondentes da pes- 
quisa atribuem valores as marcas originais iguais ou inferiores ao valor sugerido para as marcas réplicas. As diferenças em relação a este parâmetro de 35\% são encontradas nos valores referentes às marcas Mont Blanc, Lacoste e Rolex, com 25\% das respostas com valores inferiores aos valores referenciais fixados, Nike com $20 \%$, Diesel Prada e Chanel com 40\% e H. Stern com 50\% de respostas com valores iguais ou inferiores aos fixados.

Por outro lado, considerando-se que no bloco de perguntas anteriores os valores das marcas originais foram fixados e, portanto, serviriam de ancoragem adicional para a atribuição de valor para as marcas originais, $10 \%$ dos respondentes atribuíram às marcas originais superiores aos fixados para as mesmas no bloco de perguntas anterior. Exceções foram identificadas nos casos das marcas Calvin Klein, Lacoste, Nike e Tommy H., que apresentaram percentuais maiores e Rolex que não apresentou valores maiores que o fixado para sua marca original.

Estes dados reforçam o desconhecimento das marcas de luxo utilizadas neste estudo, uma vez que uma parte significativa dos respondentes da pesquisa atribuíram valores bastante díspares dos adotados como âncoras de julgamento.

Por se tratarem de marcas de luxo, posicionadas e direcionadas ao segmento de maior poder aquisitivo, ou maior faixa de renda, procedeu-se com a mesma análise de frequência por percentis, exclusivamente no segmento de respondentes que apresentaram renda superior a 10 salários mínimos, equivalente a $\mathrm{R} \$ 678,00$ na época da pesquisa. Os dados referentes a este recorte da amostra são apresentados nas TAB. 3 e 4 .

Comparando-se os dados da amostra (TAB. 1) com os dados relativos ao segmento com renda superior a 10 salários mínimos (TAB. 3) identifica-se que um percentual maior de respondentes do segmento com renda superior a 10 salários mínimos atribui valores iguais ou superiores as marcas réplicas quando fixado um valor âncora para a marca original. Em termos gerais, os resultados da amostra são 5\% inferiores aos resultados encontrados no segmento de respondentes com renda superior a 10 salários mínimos. Por exemplo, para a marca Louis Vuitton, o valor fixado para a marca original de 4950 equivale ao valor mínimo atribuído por 5\% dos 
respondentes da amostra pesquisada (percentil 95, na TAB. 1) e equivalente a $10 \%$ do valor atribuído pelo segmento de respondentes com renda superior a 10 salários mínimos (percentil 90 da TAB. 3). As exceções são as marcas Diesel e Tommy, que apresentam diferenças maiores, $10 \%$ superior no segmento com renda superior a 10 salários mínimos em relação a amostra.

Tabela 3 - Distribuição de frequência dos valores atribuídos às marcas réplicas segmento com renda superior a 10 salários mínimos

\begin{tabular}{|c|c|c|c|c|c|c|c|c|c|c|c|c|c|}
\hline \multirow{2}{*}{ Marcas } & \multicolumn{12}{|c|}{ Percentis } & \multirow{2}{*}{$\begin{array}{l}\text { Valor } \\
\text { fixado }\end{array}$} \\
\hline & 15 & 20 & 25 & 30 & 35 & 40 & 45 & 50 & 75 & 80 & 85 & 90 & \\
\hline Calvin K & 50 & 50 & 50 & 70 & 80 & 80 & 85 & 90 & 200 & 400 & 430 & 430 & 430 \\
\hline Chanel & 135 & 140 & 150 & 150 & 150 & 160 & 200 & 200 & 380 & 500 & 1000 & 1350 & 1350 \\
\hline Diesel & 80 & 99 & 100 & 120 & 120 & 130 & 150 & 150 & 800 & 870 & 870 & 870 & 870 \\
\hline Dior & 60 & 100 & 100 & 100 & 130 & 150 & 150 & 180 & 300 & 300 & 650 & 730 & 730 \\
\hline Dolce Gabana & 120 & 120 & 120 & 200 & 200 & 200 & 250 & 280 & 800 & 1200 & 5000 & 5800 & 5800 \\
\hline Gutti & 90 & 100 & 120 & 140 & 150 & 150 & 150 & 150 & 280 & 330 & 1000 & 1500 & 1500 \\
\hline H Stern & 250 & 320 & 450 & 560 & 700 & 1000 & 1000 & 1500 & 4900 & 5000 & 6500 & 6500 & 6500 \\
\hline Lacoste & 50 & 50 & 50 & 50 & 60 & 70 & 80 & 90 & 120 & 125 & 200 & 250 & 250 \\
\hline Louis Vuitton & 99 & 100 & 100 & 100 & 100 & 200 & 300 & 300 & 1000 & 1500 & 4900 & 4950 & 4950 \\
\hline Mont Blanc & 30 & 45 & 50 & 50 & 50 & 60 & 80 & 90 & 450 & 600 & 800 & 1450 & 1450 \\
\hline Nike & 80 & 90 & 90 & 100 & 120 & 150 & 150 & 150 & 200 & 230 & 300 & 600 & 600 \\
\hline Prada & 120 & 120 & 120 & 140 & 145 & 150 & 150 & 150 & 200 & 350 & 500 & 1200 & 1200 \\
\hline Rolex & 150 & 150 & 200 & 200 & 250 & 350 & 450 & 480 & 2000 & 2000 & 10000 & 18000 & 22500 \\
\hline Tommy H. & 79 & 80 & 80 & 100 & 100 & 120 & 150 & 150 & 300 & 460 & 460 & 460 & 460 \\
\hline
\end{tabular}

Fonte: Dados da pesquisa processados no SPSS

Comparando-se, por outro lado, os valores atribuídos às marcas originais a partir da fixação dos valores âncora das marcas réplicas, os percentuais de respondentes do segmento com renda superior a 10 salários mínimos que atribuem valores às marcas originais iguais ou inferiores aos valores fixados para as marcas réplica são, em termos gerais, inferiores aos percentuais de respondentes da amostra. Ou seja, menos respondentes do segmento com renda superior a 10 salários mínimos atribuem valores às marcas originais inferiores ao fixado para as marcas réplicas. Esses dados podem ser observados 
na TAB. 4. Considerando-se este recorte da pesquisa, percebe-se, que, para o segmento que poderia ser considerado como segmento alvo das marcas de luxo, o grau de atribuição de valores extremos é menor que o detectado através dos resultados da amostra. Esta avaliação por si só, entretanto, não indica que as marcas de luxo tenham um reconhecimento maior neste segmento recortado da pesquisa. Os dados levantados permitem somente afirmar que o segmento de respondentes desta pesquisa com renda superior a 10 salários mínimos atribui valores às marcas de luxo mais aceitáveis a partir das âncoras de preços utilizadas.

Tabela 4 - Distribuição de frequência dos valores atribuídos às marcas originais segmento com renda superior a 10 salários mínimos

\begin{tabular}{|c|c|c|c|c|c|c|c|c|c|c|c|c|c|}
\hline \multirow{2}{*}{ Marcas } & \multicolumn{12}{|c|}{ Percentis } & \multirow{2}{*}{$\begin{array}{l}\text { Valor } \\
\text { fixado }\end{array}$} \\
\hline & 15 & 20 & 25 & 30 & 35 & 40 & 45 & 50 & 75 & 80 & 85 & 90 & \\
\hline R Calvin K & 80 & 80 & 100 & 120 & 150 & 150 & 150 & 160 & 250 & 300 & 350 & 350 & 80 \\
\hline R Chanel & 250 & 250 & 350 & 350 & 350 & 500 & 500 & 500 & 1000 & 1000 & 1350 & 1500 & 250 \\
\hline R Diesel & 150 & 150 & 150 & 250 & 250 & 300 & 300 & 300 & 800 & 800 & 800 & 860 & 150 \\
\hline R Dior & 120 & 120 & 150 & 160 & 180 & 200 & 200 & 250 & 430 & 500 & 600 & 700 & 120 \\
\hline R Dolce Gabana & 200 & 200 & 200 & 300 & 300 & 350 & 350 & 350 & 800 & 1000 & 1800 & 2500 & 200 \\
\hline R Gutti & 120 & 120 & 180 & 200 & 240 & 250 & 250 & 280 & 700 & 800 & 900 & 900 & 120 \\
\hline R H Stern & 2500 & 2500 & 2500 & 2500 & 2500 & 2500 & 2500 & 2600 & 5000 & 5000 & 5700 & 10000 & 2.500 \\
\hline R Lacoste & 50 & 70 & 80 & 100 & 100 & 120 & 150 & 150 & 250 & 250 & 320 & 330 & 50 \\
\hline R Louis Vuitton & 250 & 250 & 250 & 350 & 500 & 500 & 800 & 800 & 2500 & 2500 & 3000 & 3500 & 250 \\
\hline R Mont Blanc & 40 & 40 & 60 & 80 & 150 & 200 & 200 & 200 & 500 & 1000 & 1500 & 1600 & 40 \\
\hline R Nike & 80 & 80 & 160 & 180 & 180 & 200 & 250 & 300 & 600 & 600 & 600 & 800 & 80 \\
\hline R Prada & 180 & 180 & 180 & 180 & 200 & 250 & 250 & 250 & 500 & 600 & 1000 & 1200 & 180 \\
\hline R Rolex & 350 & 350 & 700 & 700 & 700 & 900 & 1500 & 2000 & 15000 & 15000 & 20000 & 22500 & 350 \\
\hline R Tommy H. & 80 & 80 & 100 & 150 & 150 & 180 & 200 & 230 & 400 & 700 & 850 & 1000 & 80 \\
\hline
\end{tabular}

Fonte: Dados da pesquisa processados no SPSS

A análise dos dados de distribuição de frequência dos valores atribuídos às marcas mostrou que alguns valores atribuídos foram iguais aos valores fixados pelos pesquisadores. De maneira a aprofundar um pouco mais esta análise resolveu-se identificar o percentual de respostas que seriam iguais, superiores e inferiores aos valores fixados. Estes dados são apresentados nas TAB. 5 e 6. 
Tabela 5 - Distribuição de frequência dos valores iguais e menores atribuídos às marcas réplicas

\begin{tabular}{|c|c|c|c|c|c|c|c|c|c|}
\hline \multirow[t]{2}{*}{ Marcas } & \multirow[t]{2}{*}{$\begin{array}{l}\text { Valor } \\
\text { fixado } \\
\text { Marca } \\
\text { original }\end{array}$} & \multicolumn{2}{|c|}{$\begin{array}{l}\text { Valores atribuídos } \\
\text { à réplica iguais ao } \\
\text { fixado ao original }\end{array}$} & \multicolumn{2}{|c|}{$\begin{array}{l}\text { Valores atribuídos } \\
\text { à réplica maiores } \\
\text { que o fixado para } \\
\text { o original }\end{array}$} & \multicolumn{2}{|c|}{$\begin{array}{l}\text { Valores menores } \\
\text { que } 10\end{array}$} & \multicolumn{2}{|l|}{ Total } \\
\hline & & Freq & Percentual & Freq & Percentual & Freq & Percentual & Freq & Percentual \\
\hline Calvin K & 430 & 14 & $9,8 \%$ & 3 & $2,1 \%$ & 2 & $1,4 \%$ & 19 & $13,3 \%$ \\
\hline Chanel & 1350 & 11 & $7,7 \%$ & 1 & $0,7 \%$ & 1 & $0,7 \%$ & 13 & $9,1 \%$ \\
\hline Diesel & 870 & 17 & $11,9 \%$ & 2 & $1,4 \%$ & 0 & $0,0 \%$ & 19 & $13,3 \%$ \\
\hline Dior & 730 & 13 & $9,1 \%$ & 2 & $1,4 \%$ & 1 & $0,7 \%$ & 16 & $11,2 \%$ \\
\hline Dolce Gabana & 5800 & 12 & $8,4 \%$ & 1 & $0,7 \%$ & 2 & $1,4 \%$ & 15 & $10,5 \%$ \\
\hline Gutti & 1500 & 10 & $7,0 \%$ & 2 & $1,4 \%$ & 1 & $0,7 \%$ & 13 & $9,1 \%$ \\
\hline H Stern & 6500 & 16 & $11,2 \%$ & 2 & $1,4 \%$ & 7 & $4,9 \%$ & 25 & $17,5 \%$ \\
\hline Lacoste & 250 & 12 & $8,4 \%$ & 4 & $2,8 \%$ & 0 & $0,0 \%$ & 16 & $11,2 \%$ \\
\hline Louis Vuitton & 4950 & 12 & $8,4 \%$ & 2 & $1,4 \%$ & 6 & $4,2 \%$ & 20 & $14,0 \%$ \\
\hline Mont Blanc & 1450 & 13 & $9,1 \%$ & 3 & $2,1 \%$ & 3 & $2,1 \%$ & 19 & $13,3 \%$ \\
\hline Nike & 600 & 13 & $9,1 \%$ & 2 & $1,4 \%$ & 0 & $0,0 \%$ & 15 & $10,5 \%$ \\
\hline Prada & 1200 & 13 & $9,1 \%$ & 2 & $1,4 \%$ & 1 & $0,7 \%$ & 16 & $11,2 \%$ \\
\hline Rolex & 22500 & 11 & $7,7 \%$ & 1 & $0,7 \%$ & 0 & $0,0 \%$ & 12 & $8,4 \%$ \\
\hline Tommy H. & 460 & 15 & $10,5 \%$ & 5 & $3,5 \%$ & 1 & $0,7 \%$ & 21 & $14,7 \%$ \\
\hline
\end{tabular}

Fonte: Dados da pesquisa processados no SPSS

Os dados apresentados na TAB. 5 mostram que entre $7 \%$ e $11,9 \%$ dos respondentes atribuiu valores para as marcas réplicas iguais aos valores fixados para as marcas originais. Por outro lado entre $0,7 \%$ e $4,9 \%$ dos respondentes atribuíram valores para as marcas réplicas maiores que os valores fixados para as marcas originais e entre $0,7 \%$ e $4,2 \%$ atribuíram valores inferiores a 10 para as marcas réplicas. Com base nestes dados pode-se identificar que entre 8,4\% e 17,5\% dos respondentes atribuíram valores "diferenciados" para as marcas réplicas.

A mesma análise feita anteriormente foi repetida para o caso da atribuição de valores para as marcas originais sendo fixado o valor das marcas réplicas, conforme demonstrado na TAB. 6. 
Tabela 6 - Distribuição de frequência dos valores iguais e menores atribuídos às marcas originais

\begin{tabular}{l|l|l|l|l|l|l|l}
\hline \multirow{2}{*}{ Marcas } & \multirow{2}{*}{$\begin{array}{l}\text { Valor fixa- } \\
\text { do réplica }\end{array}$} & $\begin{array}{l}\text { Valores atribuídos } \\
\text { a original iguais à } \\
\text { réplica }\end{array}$ & \multicolumn{2}{l|}{\begin{tabular}{l}
\multicolumn{2}{l|}{ Valores atribuídos a origi- } \\
nal menores que a réplica
\end{tabular}} & \multicolumn{2}{l}{ Total } \\
\cline { 3 - 7 } R Calvin K & 80 & 31 & $21,7 \%$ & 20 & $14,0 \%$ & 51 & $35,7 \%$ \\
R Chanel & 250 & 38 & $26,6 \%$ & 22 & $15,4 \%$ & 60 & $42,0 \%$ \\
R Diesel & 150 & 40 & $28,0 \%$ & 19 & $13,3 \%$ & 59 & $41,3 \%$ \\
R Dior & 120 & 32 & $22,4 \%$ & 19 & $13,3 \%$ & 51 & $35,7 \%$ \\
R Dolce Gabana & 200 & 34 & $23,8 \%$ & 18 & $12,6 \%$ & 52 & $36,4 \%$ \\
R Gutti & 120 & 35 & $24,5 \%$ & 16 & $11,2 \%$ & 51 & $35,7 \%$ \\
R H Stern & 2500 & 38 & $26,6 \%$ & 43 & $30,1 \%$ & 81 & $56,6 \%$ \\
R Lacoste & 50 & 32 & $22,4 \%$ & 6 & $4,2 \%$ & 38 & $26,6 \%$ \\
R Louis Vuitton & 250 & 31 & $21,7 \%$ & 22 & $15,4 \%$ & 53 & $37,1 \%$ \\
R Mont Blanc & 40 & 33 & $23,1 \%$ & 10 & $7,0 \%$ & 43 & $30,1 \%$ \\
R Nike & 80 & 30 & $21,0 \%$ & 2 & $1,4 \%$ & 32 & $22,4 \%$ \\
R Prada & 180 & 39 & $27,3 \%$ & 18 & $12,6 \%$ & 57 & $39,9 \%$ \\
R Rolex & 350 & 30 & $21,0 \%$ & 16 & $11,2 \%$ & 46 & $32,2 \%$ \\
R Tommy H. & 80 & 38 & $26,6 \%$ & 13 & $9,1 \%$ & 51 & $35,7 \%$ \\
\hline
\end{tabular}

Fonte: Dados da pesquisa processados no SPSS

Neste caso, entre $21 \%$ e $28 \%$ dos respondentes atribuíram valores para as marcas originais iguais aos valores fixados para as marcas réplicas. Entre 1,4\% e 30,1\% dos respondentes atribuíram valores menores para as marcas originais quando fixados os valores para as réplicas. No total, entre $22,4 \%$ e $56,6 \%$ dos respondentes atribuíram valores iguais ou menores para as marcas originais, fixados os valores para as marcas réplicas.

Em uma análise geral dos dados levantou-se a quantidade e a representatividade dos respondentes que atribuíram valores extremos às marcas de luxo analisadas. Ou seja, procurou-se identificar a representatividade daqueles respondentes que atribuíram valores iguais ou superiores para as marcas réplicas quando se fixou valores para as marcas originais ou que fixaram valores iguais ou inferiores para as originais quando se fixou os valores para as marcas réplicas, ou seja, procurou-se identificar a representatividade dos 
respondentes que atribuíram valores extremos para todas as marcas utilizadas neste estudo, que atribuíram valores extremos à metade ou mais das marcas, à menos da metade das marcas e a nenhuma das marcas usadas no estudo. Os dados relativos a esta análise se encontram na TAB. 7.

Tabela 7 - Distribuição de frequência dos valores extremos

\begin{tabular}{l|l|l|l|l|l|l}
\hline \multirow{2}{*}{ Valores extremos } & \multicolumn{3}{|l|}{ Todos os valores atribuídos } & \multicolumn{2}{l|}{$\begin{array}{l}\text { Valor da marca original } \\
\text { fixado - Valor da marca réplica } \\
\text { atribuído }\end{array}$} & $\begin{array}{l}\text { Valor da marca réplica } \\
\text { fixado - Valor da marca } \\
\text { original atribuído }\end{array}$ \\
\hline Quantidade & Freq & Percentual & Freq & Percentual & Freq & Percentual \\
\hline Todos & 5 & $3,5 \%$ & 6 & $4,2 \%$ & 17 & $11,9 \%$ \\
\hline Metade ou mais & 17 & $11,9 \%$ & 9 & $6,3 \%$ & 34 & $23,8 \%$ \\
\hline Menos da metade & 88 & $61,5 \%$ & 28 & $19,6 \%$ & 48 & $33,6 \%$ \\
\hline Nenhum & 33 & $23,1 \%$ & 100 & $69,9 \%$ & 44 & $30,8 \%$ \\
\hline Total & 143 & $100,0 \%$ & 143 & $100,0 \%$ & 143 & $100,0 \%$ \\
\hline
\end{tabular}

Fonte: Dados da pesquisa processados no SPSS

Os dados da TAB. 7 indicam que 3,5\% do total de respondentes atribuíram todos os valores como extremos, ou seja, todos os valores atribuídos tanto para as marcas réplicas quanto para as marcas originais extrapolaram os valores fixados na pesquisa. Considerando-se, por sua vez, os valores atribuídos às marcas réplicas quando se fixou o valor da marca original, 4,2\% dos respondentes atribuíram todos os valores das 14 marcas réplicas iguais ou superiores aos valores fixados para as marcas originais, 6,3\% atribuíram valores iguais ou superiores a pelo menos metade das 14 marcas investigadas, $19,6 \%$ a menos da metade das 14 marcas investigadas e 69,9\%atribuíram valores aceitáveis. Quando a âncora de ajustamento foi fixada para as marcas réplicas e pediu-se o valor para as marcas originais, 30,8\% dos respondentes atribuíram valores considerados aceitáveis, $11,9 \%$ atribuíram valores extremos para todas as marcas originais, $23,8 \%$ atribuíram valores extremos para metade das marcas réplicas e 33,8\% atribuíram valores extremos para menos da metade das14 marcas originais. 
Com base na análise dos valores considerados extremos para esta pesquisa, ou seja, aqueles que foram identificados como iguais ou superiores para as marcas réplicas dados os valores para as marcas originais, ou iguais ou inferiores para as marcas originais dados os valores para as marcas réplicas, pode-se identificar que a ancoragem com base nos valores originais serviu como base de ajustamento mais adequada. Esta constatação é justificada uma vez que um percentual menor de respondentes atribuiu valores extremos para as marcas réplicas quando se fixou o valor das marcas originais. Estes dados encontram suporte tanto na análise feita considerando o total de respondentes por marca (TAB. 7) quanto na análise dos valores atribuídos as marcas réplicas e as marcas originais (TAB. 5 e 6).

\subsection{Análise da diferença entre valores fixados e atribuídos}

A segunda parte da análise trata da identificação das diferenças entre os valores fixados e os valores atribuídos para marcas originais e marcas réplicas. Para proceder esta análise ignoraram-se os valores considerados dados extremos identificados na análise anterior. $\mathrm{O}$ banco de dados foi utilizado, então, com todos os valores atribuídos pelos respondentes da pesquisa.

Inicialmente identificaram-se as diferenças entre os valores para a primeira pergunta (valores fixados para as marcas originais menos os valores atribuídos pelos respondentes para as marcas réplicas) e para a segunda pergunta (valores atribuídos pelos respondentes para as marcas originais menos os valores fixados para as marcas réplicas). Utilizando-se do teste de diferenças entre médias de Wilcoxon, que segundo Hair Jr. et al. (2009) se aplica melhor quando a distribuição dos valores não obedece à normalidade, verificou-se a significância estatística entre as médias obtidas. Estes dados são apresentados na TAB. 8.

A análise dos dados da TAB. 8 mostra que a diferença entre as médias das diferenças foi estatisticamente significativa para as marcas analisadas. Identificou-se também que em todos os produtos, o desvio padrão se mostra superior na diferença 2. Tal fato leva a inferir que os dados encontrados nos resultados individuais de precificação dos produtos, nesta fase da pesquisa, se mostram mais dispersos, ou seja, há uma maior variação dos valores atribuídos aos produtos originais quando o valor da réplica foi fixado. 
A Percepção de Marcas de Luxo em uma Era de "Populismo" de Réplicas: um Estudo a Partir da Ancoragem de Preços

Tabela 8- Análise das diferenças entre valores fixados e valores atribuídos

\begin{tabular}{|c|c|c|c|c|c|c|}
\hline Marcas & Diferenças & Média & Desvio Padrão & Mínimo & Máximo & $\begin{array}{l}\text { Sig. (2-tai- } \\
\text { led) }\end{array}$ \\
\hline \multirow{2}{*}{ Louis Vuitton } & Diferença 1 & $4.079,50$ & $1.494,78$ & $-40,00$ & $4.950,00$ & \multirow{2}{*}{,000 } \\
\hline & Diferença 2 & $1.476,57$ & $2.871,53$ & $-210,00$ & $24.750,00$ & \\
\hline \multirow{2}{*}{ Tommy Hilfiger } & Diferença 1 & 285,27 & 143,90 & $-240,00$ & 460,00 & \multirow{2}{*}{,002 } \\
\hline & Diferença 2 & 362,59 & $1.089,14$ & $-70,00$ & $7.920,00$ & \\
\hline \multirow{2}{*}{ H Stern } & Diferença 1 & $4.415,85$ & $2.269,13$ & $-3.500,00$ & $6.500,00$ & \multirow{2}{*}{,000 } \\
\hline & Diferença 2 & $1.336,83$ & $4.173,96$ & $-2.498,00$ & $27.500,00$ & \\
\hline \multirow{2}{*}{ Diesel } & Diferença 1 & 609,14 & 262,46 & 0,00 & 870,00 & \multirow{2}{*}{,000 } \\
\hline & Diferença 2 & 552,84 & $2.160,73$ & $-135,00$ & $14.850,00$ & \\
\hline \multirow{2}{*}{ Mont Blanc } & Diferença 1 & $1.110,29$ & 455,99 & $-50,00$ & $1.450,00$ & \multirow{2}{*}{,000 } \\
\hline & Diferença 2 & 523,97 & $1.202,84$ & $-39,00$ & $9.960,00$ & \\
\hline \multirow{2}{*}{ Calvin Klein } & Diferença 1 & 297,23 & 146,11 & $-570,00$ & 430,00 & \multirow{2}{*}{,000 } \\
\hline & Diferença 2 & 452,04 & $1.374,48$ & $-65,00$ & $7.920,00$ & \\
\hline \multirow{2}{*}{ Dolce Gabana } & Diferença 1 & $4.882,87$ & $1.682,33$ & 0,00 & $5.800,00$ & \multirow{2}{*}{,000 } \\
\hline & Diferença 2 & 707,42 & $2.411,31$ & $-185,00$ & $19.800,00$ & \\
\hline \multirow{2}{*}{ Dior } & Diferença 1 & 511,78 & 210,16 & $-40,00$ & 730,00 & \multirow{2}{*}{,000 } \\
\hline & Diferença 2 & 404,35 & $1.511,41$ & $-110,00$ & $11.880,00$ & \\
\hline \multirow{2}{*}{ Lacoste } & Diferença 1 & 154,73 & 80,43 & $-250,00$ & 250,00 & \multirow{2}{*}{,001 } \\
\hline & Diferença 2 & 334,12 & $1.038,62$ & $-20,00$ & $7.950,00$ & \\
\hline \multirow{2}{*}{ Rolex } & Diferença 1 & $18.743,57$ & $6.434,18$ & 0,00 & $22.500,00$ & \multirow{2}{*}{,000 } \\
\hline & Diferença 2 & $5.023,76$ & $17.567,23$ & $-341,00$ & $199.650,00$ & \\
\hline \multirow{2}{*}{ Prada } & Diferença 1 & 895,55 & 362,80 & $-1.000,00$ & $1.200,00$ & \multirow{2}{*}{,000 } \\
\hline & Diferença 2 & 407,37 & $1.075,73$ & $-165,00$ & $8.820,00$ & \\
\hline \multirow{2}{*}{ Chanel } & Diferença 1 & $1.011,77$ & 362,38 & 0,00 & $1.350,00$ & \multirow{2}{*}{,000 } \\
\hline & Diferença 2 & 484,80 & $1.134,18$ & $-235,00$ & $8.750,00$ & \\
\hline \multirow{2}{*}{ Gutti } & Diferença 1 & $1.202,65$ & 406,03 & $-50,00$ & $1.500,00$ & \multirow{2}{*}{,000 } \\
\hline & Diferença 2 & 322,73 & 880,64 & $-108,00$ & $8.880,00$ & \\
\hline \multirow{2}{*}{ Nike } & Diferença 1 & 383,57 & 178,30 & $-600,00$ & 600,00 & \multirow{2}{*}{,000 } \\
\hline & Diferença 2 & 252,33 & 458,99 & $-20,00$ & $4.920,00$ & \\
\hline
\end{tabular}

Fonte: Dados da pesquisa processados no SPSS

Nota: Diferença 1 se refere à diferença entre o valor da marca original fixado e o valor da marca réplica atribuído pelo respondente. Diferença 2 se refere à diferença entre o valor de marca réplica fixado e o valor da marca original atribuído pelo respondente 
Identificou-se também que as diferenças são maiores quando se fixou o valor da marca original e pediu-se o valor para a marca réplica (diferença 1). As únicas exceções a esta afirmação são os valores encontrados para as marcas Tommy Hilfiger, Calvin Klein e Lacoste, que tiveram a diferença 2 com valores maiores que a diferença 1. Observando-se o resultado das demais marcas é possível inferir que a ancoragem funcionou nos dois sentidos, uma vez que ao fixar valores mais elevados (marcas originais fixados) os valores encontrados foram maiores (marcas réplicas atribuídos), e, contrariamente, ao se fixar valores mais baixos para as marcas réplicas os valores encontrados para as marcas originais foram mais baixos.

A análise da amplitude se refere à análise da diferença entre os valores fixados na pesquisa e os valores atribuídos pelos respondentes. Neste sentido, resolveu-se comparar a amplitude encontrada com a amplitude fixada, ou seja, comparar a diferença entre os valores atribuídos pelos respondentes e os valores fixados pela pesquisa com a diferença entre os valores fixados pela pesquisa. Este raciocínio parte do princípio que, hipoteticamente, as diferenças encontradas entre os valores atribuídos pelos respondentes e os valores fixados deveriam estar próximas das diferenças entres os dois valores fixados, para as marcas originais e as marcas réplicas, que funcionariam como limites superiores e inferiores para os valores encontrados. As comparações entre estes dados são apresentadas na TAB. 9.

Os dados da TAB. 9 indicam maior proximidade entre as diferenças 1 e a diferença entre os valores fixados, significando que a fixação do valor da marca original gera uma percepção de diferença entre original e réplica mais próxima da realidade do que quando se fixa o valor para a marca réplica. Estes dados reforçam que a os valores das marcas originais utilizadas como âncoras permitem identificar valores para as réplicas mais realistas, do que quando as âncoras de preço são adotadas a partir da fixação de valores para as marcas réplicas. 
Tabela 9 - Comparação entre diferenças fixadas e diferenças atribuídas

\begin{tabular}{|c|c|c|c|c|c|c|c|}
\hline Marca & & $\begin{array}{l}\text { Valores } \\
\text { Fixados }\end{array}$ & $\begin{array}{l}\text { Diferença } \\
\text { entre Valo- } \\
\text { res Fixados }\end{array}$ & Diferenças & $\begin{array}{l}\text { Média das } \\
\text { diferenças }\end{array}$ & $\begin{array}{l}\text { Desvio } \\
\text { Padrão }\end{array}$ & Percentual ${ }^{a}$ \\
\hline \multirow{2}{*}{$\begin{array}{l}\text { Louis } \\
\text { Vuitton }\end{array}$} & Original & $4.950,00$ & \multirow{2}{*}{$4.700,00$} & Diferença 1 & $4.079,50$ & $1.494,78$ & 86,80 \\
\hline & Réplica & 250,00 & & Diferença 2 & $1.476,57$ & $2.871,53$ & 31,42 \\
\hline \multirow{2}{*}{$\begin{array}{l}\text { Tommy } \\
\text { Hilfiger }\end{array}$} & Original & 460,00 & \multirow{2}{*}{380,00} & Diferença 1 & 285,27 & 143,90 & 75,07 \\
\hline & Réplica & 80,00 & & Diferença 2 & 362,59 & $1.089,14$ & 95,42 \\
\hline \multirow{2}{*}{ H Stern } & Original & $6.500,00$ & \multirow{2}{*}{$4.000,00$} & Diferença 1 & $4.415,85$ & $2.269,13$ & 110,40 \\
\hline & Réplica & $2.500,00$ & & Diferença 2 & $1.336,83$ & $4.173,96$ & 33,42 \\
\hline \multirow{2}{*}{ Diesel } & Original & 870,00 & \multirow{2}{*}{720,00} & Diferença 1 & 609,14 & 262,46 & 84,60 \\
\hline & Réplica & 150,00 & & Diferença 2 & 552,84 & $2.160,73$ & 76,78 \\
\hline \multirow{2}{*}{ Mont Blanc } & Original & $1.450,00$ & \multirow{2}{*}{$1.410,00$} & Diferença 1 & $1.110,29$ & 455,99 & 78,74 \\
\hline & Réplica & 40,00 & & Diferença 2 & 523,97 & $1.202,84$ & 37,16 \\
\hline \multirow{2}{*}{$\begin{array}{l}\text { Calvin } \\
\text { Klein }\end{array}$} & Original & 430,00 & \multirow{2}{*}{350,00} & Diferença 1 & 297,23 & 146,11 & 84,92 \\
\hline & Réplica & 80,00 & & Diferença 2 & 452,04 & $1.374,48$ & 129,15 \\
\hline \multirow{2}{*}{$\begin{array}{l}\text { Dolce } \\
\text { Gabana }\end{array}$} & Original & $5.800,00$ & \multirow{2}{*}{$5.600,00$} & Diferença 1 & $4.882,87$ & $1.682,33$ & 87,19 \\
\hline & Réplica & 200,00 & & Diferença 2 & 707,42 & $2.411,31$ & 12,63 \\
\hline \multirow{2}{*}{ Dior } & Original & 730,00 & \multirow{2}{*}{610,00} & Diferença 1 & 511,78 & 210,16 & 83,90 \\
\hline & Réplica & 120,00 & & Diferença 2 & 404,35 & $1.511,41$ & 66,29 \\
\hline \multirow{2}{*}{ Lacoste } & Original & 250,00 & \multirow{2}{*}{200,00} & Diferença 1 & 154,73 & 80,43 & 77,37 \\
\hline & Réplica & 50,00 & & Diferença 2 & 334,12 & $1.038,62$ & 167,06 \\
\hline \multirow{2}{*}{ Rolex } & Original & $22.500,00$ & \multirow{2}{*}{$22.150,00$} & Diferença 1 & $18.743,57$ & $6.434,18$ & 84,62 \\
\hline & Réplica & 350,00 & & Diferença 2 & $5.023,76$ & $17.567,23$ & 22,68 \\
\hline \multirow{2}{*}{ Prada } & Original & $1.200,00$ & \multirow{2}{*}{$1.020,00$} & Diferença 1 & 895,55 & 362,80 & 87,80 \\
\hline & Réplica & 180,00 & & Diferença 2 & 407,37 & $1.075,73$ & 39,94 \\
\hline \multirow{2}{*}{ Chanel } & Original & $1.350,00$ & \multirow{2}{*}{$1.100,00$} & Diferença 1 & $1.011,77$ & 362,38 & 91,98 \\
\hline & Réplica & 250,00 & & Diferença 2 & 484,80 & $1.134,18$ & 44,07 \\
\hline \multirow{2}{*}{ Gutti } & Original & $1.500,00$ & \multirow{2}{*}{$1.380,00$} & Diferença 1 & $1.202,65$ & 406,03 & 87,15 \\
\hline & Réplica & 120,00 & & Diferença 2 & 322,73 & 880,64 & 23,39 \\
\hline Nike & $\begin{array}{l}\text { Original } \\
\text { Réplica }\end{array}$ & $\begin{array}{l}600,00 \\
80,00\end{array}$ & 520,00 & $\begin{array}{l}\text { Diferença } 1 \\
\text { Diferença } 2\end{array}$ & $\begin{array}{l}383,57 \\
252,33\end{array}$ & $\begin{array}{l}178,30 \\
458,99\end{array}$ & $\begin{array}{l}73,76 \\
48,52\end{array}$ \\
\hline
\end{tabular}

Fonte: Dados da pesquisa processados no SPSS

Nota: $\left({ }^{a}\right)$ Representa o percentual da média das diferenças sobre a diferença entre os valores fixados. Diferença 1 se refere à diferença entre o valor da marca original fixado e o valor da marca réplica atribuído pelo respondente. Diferença 2 se refere à diferença entre o valor de marca réplica fixado e o valor da marca original atribuído pelo respondente 


\section{CONSIDERAÇões FINAIS}

Muitas das tarefas diárias das pessoas requerem julgamentos e, desta forma, podem estar propensas aos efeitos da heurística da ancoragem, mostrando que julgamentos de precificação incertos são direcionados pelo valor de uma âncora. As heurísticas confirmam as limitações cognitivas dos seres humanos (MUSSWEILER; STRACK, 2001) e é difícil evitar seus efeitos.

A supressão da lógica favorece o estabelecimento de um círculo vicioso, pois os resultados dos julgamentos realizados por regras heurísticas, no caso analisado, na precificação de produtos, são satisfatórios para o sujeito, o que torna a utilização de atalhos mentais frequentes e, portanto, suscetíveis a erros e vieses.

Neste estudo a amostra foi constituída por 134 respondentes, em maior proporção respondentes do sexo feminino (65\%) e estado civil predominante o "solteiro" (54,4\%). A análise dos dados coletados na pesquisa foi realizada em duas etapas.

Inicialmente, foi utilizada a fixação de percentis variados, de maneira a possibilitar grande amplitude de análise. Os dados demonstraram que fixados os valores para as marcas originais, 5\% (equivalente ao percentil 95) dos respondentes atribuíram valores iguais ou superiores a estes para as marcas réplicas. A partir de valores fixados para as marcas réplicas, identificou que 35\% dos respondentes atribuíram valores as marcas originais iguais ou inferiores ao valor sugerido para as marcas réplicas. Estes dados parecem indicar, inicialmente, o desconhecimento das marcas de luxo utilizadas neste estudo por parte da amostra de respondentes da pesquisa.

Aspecto interessante a ser observado com o presente estudo refere-se ao nível de renda dos respondentes em relação a propensão da ancoragem. Apurou-se que por se tratarem de marcas de luxo, posicionadas e direcionadas ao segmento de maior poder aquisitivo, ou maior faixa de renda, um percentual maior de respondentes do segmento com renda superior a 10 salários mínimos atribuiu valores iguais ou superiores as marcas réplicas quando fixado um valor âncora para a marca original. Em termos gerais, os resultados da 
amostra são 5\% inferiores aos resultados encontrados no segmento de respondentes com renda superior a 10 salários mínimos, o que indica a importância do posicionamento da marca para o público alvo.

A análise dos dados de distribuição de frequência dos valores atribuídos às marcas mostrou que alguns valores atribuídos foram iguais aos valores fixados pelos pesquisadores e que todos os valores atribuídos tanto para as marcas réplicas quanto para as marcas originais extrapolaram os valores fixados na pesquisa.

A segunda parte da análise tratou da identificação das diferenças entre os valores fixados e os valores atribuídos para marcas originais e marcas réplicas a diferença entre as médias das diferenças foi estatisticamente significativa para as marcas analisadas, ou seja, há uma maior variação dos valores atribuídos aos produtos originais quando o valor da réplica foi fixado. Identificou-se também que as diferenças são maiores quando se fixou o valor da marca original e pediu-se o valor para a marca réplica

Os dados desta pesquisa, analisados a partir de técnicas estatísticas diferentes, a identificação de dados extremos e a análise da amplitude da diferença entre os valores fixados na pesquisa e os valores atribuídos pelos respondentes, levam a duas constatações diferentes e complementares. A primeira se refere ao desconhecimento das marcas de luxo utilizadas neste estudo, identificado a partir da análise dos dados extremos levantados. Este conjunto de dados, como apontado na primeira parte da análise da pesquisa, aponta que ao serem solicitados a atribuir valores para as marcas os respondentes "inferem" valores, que podem ser interpretados como declaração de que "não faço a menor ideia dos valores reais ou possíveis" que as marcas teriam. Ou seja, que não conhecem tais marcas e que, portanto, não têm referência de valores para atribuírem às marcas, sejam elas originais ou réplicas.

A segunda constatação se refere à âncora de preço baseada no valor original como de maior validade para julgamento do valor da marca réplica, ou seja, quando são fornecidas informações relativas à marca original é mais fácil, ou "mais próximo da realidade" o 
julgamento e identificação de uma réplica do que quando se fornecem informações sobre as réplicas e se solicita o julgamento ou identificação de marcas originais. Esclarecendo-se ainda mais esta constatação, os dados da pesquisa apontam que é mais fácil identificar uma réplica quando se tem informações sobre a marca original do que se identificar a marca original quando as informações partem das marcas réplicas.

As análises e constatações feitas nesta pesquisa apontam para a necessidade de uma gestão de marcas mais cuidadosa e estratégica por parte das empresas detentoras de marcas de luxo. Considerandose a atratividade das marcas de luxo como referenciais significativos e simbólicos de status e poder, como referenciado anteriormente, as marcas réplicas tendem a serem substitutas aceitáveis em segmentos sociais que não têm conhecimento das marcas de luxo, como ressaltado na pesquisa de Strehlau e Peters Filho (2006).

Ou seja, se determinado produto tem sua marca amplamente reconhecida como uma marca de luxo, como indicação simbólica de status e distinção social de seu possuidor, mas não tem seus atributos e características de produto conhecidos, pode facilitar a adoção da réplica na ocupação simbólica do espaço destinado à marca original. Um consumidor pode dar preferência à aquisição de uma marca réplica ou falsificada de um produto de luxo e passar a deter e exprimir-se pelos valores simbólicos atribuídos à marca de luxo original, uma vez que, monetariamente seu gasto será menor, e, principalmente, não será reconhecido como consumidor "falsificador", pois, seu grupo de referência e demais consumidores não são capazes de identificar as características e atributos diferenciadores dos produtos de luxo que lhes conferem tal denominação, conforme pontuado por Gentry et al. (2001) .

Por outro lado, mas de forma complementar, ao identificar-se que informações relativas às marcas originais são âncoras mais eficientes para identificação de marcas réplicas ou falsificadas, a gestão estratégica das marcas de luxo ao direcionarem a construção de suas marcas para o mercado como um todo e não somente para 
seus segmentos alvo de consumo, ampliando o espectro de canais e receptores de suas comunicações institucionais e de produtos reforçariam sua identidade de valor e permitiriam a diferenciação e distanciamento das marcas réplicas. Esta abordagem ampliada da estratégia de comunicação das marcas levaria, não somente a esta possibilidade de reconhecimento das réplicas e falsificações, facilitando o combate legal destas práticas, mas, de forma complementar, permitiria minimizar a utilização de réplicas e falsificações ao instruir e fornecer ao mercado como um todo informações sobre os atributos de valor das marcas originais que a diferenciam e constituem sua identidade única e não imitável. O amplo conhecimento destes atributos originais permitiria aos consumidores não alvo das marcas de luxo identificarem consumidores que utilizam marcas réplicas como alavancagem social distintiva. A instrumentalização do mercado para "desmascarar" consumidores de falsificações reforçaria o posicionamento de valor e diferenciação das marcas de luxo.

Naturalmente que os dados levantados nesta pesquisa se referem ao conjunto de respondentes. As análises e recomendações feitas, entretanto, servem de alerta e questionamento para os gestores das marcas de luxo e visam contribuir para a eficácia da gestão destas marcas e também para o combate à pirataria e falsificações.

Como em todos os demais estudos que adotam perspectivas metodológicas diferentes, sugere-se que novos estudos sejam desenvolvidos, utilizando-se outras marcas e outras categorias de produtos de modo a ampliar as descobertas feitas.

\section{REFERÊNCIAS}

ASSOCIAÇÃO BRASILEIRA DE EMPRESAS DE LUXO - ABRAEL. O que é mercado do luxo no Brasil. 2013. Disponível em: <http://www.abrael.org.br/artigos.php?id=1\&pag_n=1>. Acesso em: 12 set. 2016.

BARBOSA L.; CAMPBELL, C. Cultura, consumo e identidade. Rio de Janeiro: FGV, 2006. BAKER, H. K., NOFSINGER, J. R. Psychological biases of investors. Financial Services Review, New York, v. 11, n.2, p. 97-116, 2002. 
BATEY, M. O Significado da Marca: como as pessoas ganham a vida na mente dos consumidores. Rio de Janeiro: Best Business, 2010.

BEZERRA, J.; LEONE, R. Efeito ancoragem e relações de consumo: um estudo com produtos da cesta básica. Revista Ambiente Contábil, v. 5, n. 2, p. 68-85, 2013.

CASTARÈDE, J. O luxo: os segredos dos produtos mais desejados do mundo. São Paulo: Barcarolla, 2005.

CHAPMAN, G. B.; JOHNSON, E. J. Anchoring, activation, and the construction of values. Organizational Behavior and Human Decision Processes, v. 79, n. 2, p. 115-153, 1999.

COOPER, D. R.; SCHINDLER, P. S. Métodos de pesquisa em administração. 7. ed. Porto Alegre: Bookman, 2003.

CRESCITELLI, E.; FIGUEIREDO, J. B. C. Brand equity evolution: a system dynamics model. BAR, Curitiva, v. 6, n. 2, art. 2, p. 101-117, 2009.

DOUGLAS, M.; ISHERWOOD, B. O mundo dos bens: para uma antropologia do consumo. Rio de Janeiro: UFRJ, 2009.

GALHANONE, R. Valor percebido pelo consumidor de produtos de luxo: proposição de um modelo teórico. Tese de Doutorado Apresentada a Universidade Federal de São Paulo - USP. São Paulo, 2013.

GENTRY, J.; PUTREVU, S.; SHUTZ, C.; COMMURI, S. How now ralf lauren? the separation of brand and product in a counterfeit culture. Advances in Consumer Research, v.28, n.1, p.258-265, 2001.

GIESBRECHT, C. O Consumo de Marcas Consagradas no Mercado Pirata. Dissertação de mestrado apresentada a Universidade Estadual do Ceará, 2010.

GROSSMAN, G. M.; SHAPIRO, C. Foreign counterfeiting of status goods. The Quarterly Journal of Economics, v. 103, n. 1, p. 79-100, 1988.

HAIR JR. J. F. et al. Análise Multivariada de Dados. Porto Alegre: Bookman, 2009.

HOEFFLER, S.; KELLER, K. L. The marketing advantages of strong brands. Journal of Brand Management, v. 10, n. 6, p. 421-455, 2003. 
JORNAL DO BRASIL. Luxo no Brasil deve movimentar €3 bilhões. 2013. Disponível em: http://www.jb.com.br/economia/noticias/2013/12/07/luxo-no-brasil-deve-movimentar-3-bilhoes-em-2013-avalia-bain-company/. Acesso em 03 de maio de 2016.

KLEIN, N. Sem logo: a tirania das marcas em um país vendido. Rio de janeiro: Record, 2003.

LICHTENSTEIN, S., SLOVIC, P. Reversals of preference between bids and choices in gambling decisions. Journal of Experimental Psychology, v. 89, n.1, p. 46-55, 1971.

LIPOVETSKY, G.; ROUX, E. O luxo eterno: da idade do sagrado ao tempo das marcas. São Paulo: Companhia das letras, 2005.

MUSSWEILER, T.; STRACK, F. The semantics of anchoring. Organizational Behavior and Human Decision Processes, v. 86, n. 2, p. 234-255, 2001.

PEREIRA, L. C. J. et at. Brasil: Estratégias do Luxo. In: ENCONTRO DE ESTUDOS DE ESTRATÉGIA ANPAD - 3Es, 2., 2007, São Paulo. Anais... Rio de Janeiro: ANPAD, 2007.

RAO, A. R.; MONROE, K. B. The effect of price, brand name, and store name on buyers'perceptions of product quality. Journal of Marketing Research, v. 26, n. 3, p. 351357, 1989.

SEMPRINI, A. A marca pós-moderna: poder, fragilidade da marca na sociedade contemporânea. São Paulo: Estação das Letras, 2010.

STRACK, F.; MUSSWEILER, T. Explaining the enigmatic anchoring effect: Mechanisms of selective accessibility. Journal of Personality and Social Psychology, v. 73, n. 3, p. 437-446, 1997.

STREHLAU, S.; PETERS FILHO, T. A. Valor para o cliente de artigos de luxo falsificados: entre o blefe e o prestígio. In: ENCONTRO DE MARKETING DA ANPAD - EMA, 2., 2006, Rio de Janeiro. Anais... Rio de Janeiro: ANPAD, 2006.

TAVARES, M. C. Gestão de Marcas: construindo marcas de valor. São Paulo: Harbra, 2008.

TONETTO, L. M. et al. O papel das heurísticas no julgamento e na tomada de decisão sob incerteza. Estud. psicol., Campinas, v. 23, n. 2, p. 181-189, jun. 2006.

TRINDADE, T. O. Identidades e Representações: Significados Associados ao Consumo de Pirataria. In: ENCONTRO DE MARKETING DA ANPAD - EMA, 3., 2008, Curitiba. Anais... Rio de Janeiro: ANPAD, 2008. 
TRIVIÑOS, A. N. S. Introdução à pesquisa em ciências sociais: a pesquisa qualitativa em educação. São Paulo: Atlas, 2012.

TVERSKY, A.; KAHNEMAN, D. Judgment under uncertainty: heuristics and biases. Science, v. 185, n. 4157, p. 1124-1131, 1974.

Recebido em: 30-1-2017

Aprovado em: 26-4-2017

Avaliado pelo sistema double blind review.

Editor: Elmo Tambosi Filho

Disponível em http://mjs.metodista.br/index.php/roc 